Pathophysiology

of Haemostasis and Thrombosis

\title{
Identification and Localization of Heparin-Binding Region of Snake Venom VEGF and Its Blocking of VEGF-A165
}

\author{
Yuko Tokunaga Yasuo Yamazaki Takashi Morita \\ Department of Biochemistry, Meiji Pharmaceutical University, Noshio, Kiyose, Tokyo, Japan
}

\section{Key Words}

Vascular endothelial growth factor · Snake venom •

Heparin-binding protein

\begin{abstract}
Vascular endothelial growth factor (VEGF-A165) displays diverse effects through binding to its receptor, KDR (kinase domain-containing receptor). Heparan sulfate/heparin-like molecules greatly contribute to their interaction. Indeed, the mitogenic potency of VEGF-A165 lacking the $\mathrm{C}$-terminal heparin-binding region is less than $1 \% \mathrm{com}$ pared with intact VEGF-A165. We previously found novel heparin-binding VEGFs, designated VEGF-F that specifically recognizes KDR in snake venoms. VEGF-Fs almost completely lack the C-terminal heparin-binding region compared with VEGF-A165, despite their heparinbinding potential. In this study, we attempted to identify the heparin-binding region of VEGF-F using synthetic peptides. We have demonstrated that the heparin-binding site of VEGF-F is located in its $\mathrm{C}$-terminal region, particularly localized on the $\mathrm{N}$-terminal portion of this region. Furthermore, a synthetic peptide of this region blocks the biological activity of VEGF-A165 in vitro and in vivo.
\end{abstract}

\section{Vascular Endothelial Growth Factor (VEGF) and Heparin-Binding Potential}

Vascular endothelial growth factor (VEGF-A165) displays multiple effects, such as promoting endothelial growth and vascular permeability and hypotension, through binding to its receptor, KDR (kinase domaincontaining receptor) [1-3]. Heparan sulfate/heparin-like molecules are known to greatly modulate their interaction (fig. 1). In fact, the mitogenic potency of VEGF-A165 lacking the $\mathrm{C}$-terminal heparin-binding region (55-amino acid residues) is less than $1 \%$ compared with that of intact VEGF-A165 [4].

We previously reported the isolation and characterization of two novel heparin-binding VEGF, designated vammin and VR-1, from two distinct viper venoms [5]. Vammin and VR-1 exhibit more potent biological activity when compared to VEGF-A165 and selectively recognize KDR rather than other VEGF receptors [5]. Due to their unique receptor selectivity and biological properties, we proposed a new subtype, VEGF-F, for snake venom-derived VEGFs that specifically recognize KDR.

VEGF-A165 is an $\sim 45-\mathrm{kDa}$ homodimeric glycoprotein possessing a 55-residue basic heparin-binding region in its C-terminus. A C-terminal-deficient form of VEGFA165 (110 residues) generated by plasmin digestion was

\section{KARGER \\ Fax +4161306 1234 E-Mail karger@karger.ch} www.karger.com 
Fig. 1. Schematic model of the interaction between VEGF-A165, KDR, and heparin. VEGF-A165 is composed of two domains, an N-terminal receptor-binding domain (grey) and a C-terminal heparin-binding domain (dark grey). Heparin/heparan sulfate-like molecules modulate the interaction between VEGF-A165 and KDR by binding via $\mathrm{C}$-terminal heparin-binding domain.

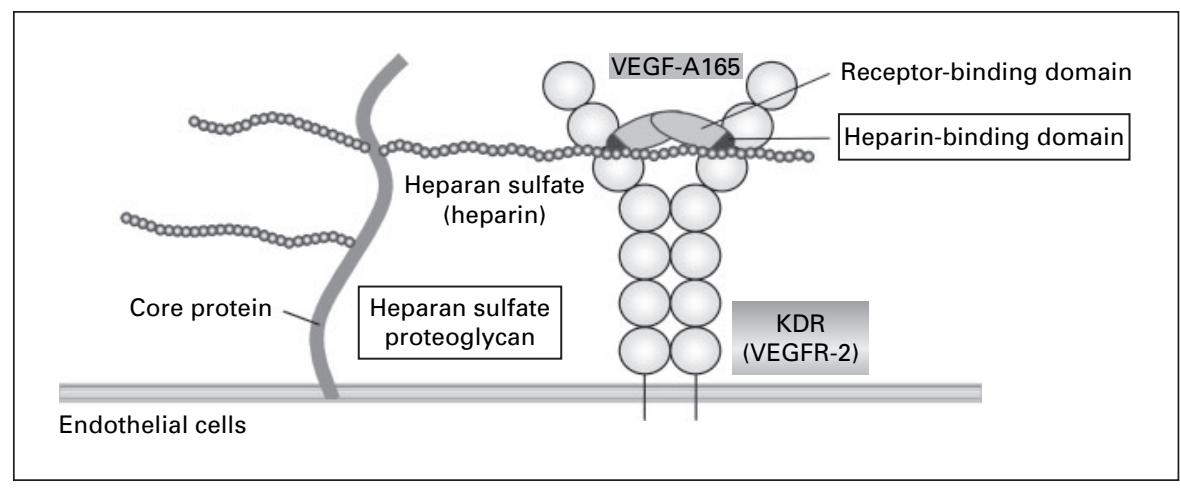

not retained from a heparin affinity column and displayed markedly reduced (greater than 100-fold) potency of growth factor activity when compared with intact VEGFA165 [4]. VEGF-Fs are 25-kDa homodimeric heparinbinding proteins. The primary structure of VEGF-Fs possesses $\sim 50 \%$ identity with that of VEGF-A 165 , and they have a markedly short $\mathrm{C}$-terminal portion (16-17 amino acid residues) when compared with VEGF-A165. This region does not include cysteine bridges, and does not show any significant homology with other proteins or domains, including the $\mathrm{C}$-terminal heparin-binding region of other VEGF subtypes.

We herein report the C-terminal region of VEGF-F fully mediates its heparin-binding activity and inhibits the biological activity of VEGF-A165 in vitro and in vivo. These results suggest that the C-terminal peptide of VEGF-F inhibits the biological activity of VEGF-A165 via binding to heparin-like molecules.

\section{Identification of Heparin-Binding Region of Snake Venom VEGF and VEGF-Blocking Activity}

We first synthesized the C-terminal region of vammin (corresponding to residues $94-110 ; 17$ residues), designated peptide 1 . Peptide 1 was purified by two steps column chromatography; heparin affinity chromatography followed by reversed-phase HPLC. Peptide 1 and intact vammin were tested for heparin-binding ability using heparin affinity chromatography. Heparin-binding potential of vammin and peptide 1 were virtually equivalent as determined by the $\mathrm{NaCl}$ concentrations required for elution ( 0.33 and $0.36 \mathrm{M}$, respectively), indicating that the heparin-binding activity is completely mediated by the C-terminal region.

Identification of Heparin-Binding Region of Snake Venom VEGF
We speculated that if the C-terminal heparin-binding region of vammin recognizes similar heparin structures, it competes with VEGF-A165 on the endothelial surface and inhibits the biological activities of VEGF-A165. The effect of peptide 1 on endothelial cell proliferation activity of vammin or VEGF-A165 was thus investigated. Peptide 1 completely inhibited both vammin- and VEGFA165-stimulated endothelial proliferation with similar $\mathrm{IC}_{50}$ values (320 and $280 \mu M$, respectively). We also examined the effect of peptide 1 on rat arterial blood pressure in vivo. Administration of peptide $1(3 \mu \mathrm{g} / \mathrm{g}, 5 \mathrm{~min}$ before following vammin administration) via femoral vein completely blocked the vammin $(0.1 \mu \mathrm{g} / \mathrm{g})$-induced hypotensive effect. In contrast, a higher dose of peptide $1(30 \mu \mathrm{g} / \mathrm{g})$ was required to completely inhibit VEGFA165-induced hypotension. These results indicate that peptide 1 is able to block the biological activity of VEGFA165 even in vivo.

\section{Further Localization of Heparin-Binding Site in Peptide 1 Sequence}

To further investigate localization of heparin-binding site of peptide 1, we synthesized two additional peptides that correspond to $\mathrm{N}$ - or C-terminal part of peptide 1, designated peptide 2 (corresponding to residues 94-101; 9 residues) and peptide 3 (corresponding to residues $102-$ $110 ; 11$ residues), respectively. The heparin-binding potential of synthetic peptides was assessed by heparin affinity chromatography. Peptide 2 was eluted at $0.34 \mathrm{M}$ $\mathrm{NaCl}$, showing almost identical activity to vammin and peptide 1 for heparin binding. In contrast, peptide 3 was not retained after washing the column with $\mathrm{NaCl}$-free buffer, indicating substantially lower affinity to the heparin column. These data indicate that the basic residues 
clustered in the N-terminal portion of peptide 1 primarily mediate the heparin-binding function.

We next evaluated the effect of synthetic peptides on VEGF-A165 activity using cultured human umbilical vein endothelial cells. Relatively weak inhibition was observed in peptide 2-treated cells when compared with peptide 1, while peptide 3 had an even smaller effect, thus showing good agreement with the heparin-binding affinity data. These results strongly suggest that the basic amino acid residues in peptide 2 primarily mediate the heparin-binding activity of VEGF-Fs, but are not sufficient for binding and that the C-terminal portion (peptide 3 region) is also involved in the interaction. In addition, we also estimated the effect of synthetic peptides on VEGFA165-induced hypotension. When pre-treatment of peptide 2, VEGF-A165-induced hypotension completely blocked as well as pre-treatment of peptide 1. These in vivo data show good agreement with the in vitro results obtained using cultured endothelial cells.

\section{Conclusion}

In conclusion, we have demonstrated that the heparinbinding site of VEGF-F is located in its C-terminal short region, particularly localized in the $\mathrm{N}$-terminal portion of peptide 1 region. Furthermore, a synthetic peptide of this region blocks the biological activity of VEGF-A165 in vitro and in vivo. Because this heparin-binding region has a relatively small structure, it may be a valuable tool for designing new anticancer drugs that target VEGF-heparin interaction.

\section{References}

-1 Takahashi T, Yamaguchi S, Chida K, Shibuya M: A single autophosphorylation site on KDR/ Flk-1 is essential for VEGF-A-dependent activation of PLC-gamma and DNA synthesis in vascular endothelial cells. EMBO J 2001;20: 2768-2778.

-2 Murohara T, Horowitz JR, Silver M, Tsurumi Y, Chen D, Sullivan A, Isner JM: Vascular endothelial growth factor/vascular permeability factor enhances vascular permeability via nitric oxide and prostacyclin. Circulation 1998; 97:99-107.
>3 Li B, Ogasawara AK, Yang R, Wei W, He GW, Zioncheck TF, Bunting S, de Vos AM, Jin H: $\mathrm{KDR}$ (VEGF receptor 2) is the major mediator for the hypotensive effect of VEGF. Hypertension 2002;39:1095-1100.
$>4$ Keyt BA, Berleau LT, Nguyen HV, Chen H, Heinsohn H, Vadlen R, Ferrara N: The carboxyl-terminal domain (111-165) of vascular endothelial growth factor is critical for its mitogenic potency. J Biol Chem 1996;271:77887795.

$\checkmark 5$ Yamazaki Y, Takani K, Atoda H, Morita T: Snake venom vascular endothelial growth factors (VEGFs) exhibit potent activity through their specific recognition of KDR (VEGF receptor 2). J Biol Chem 2003;278:5198551988. 